\title{
(2) OPEN ACCESS \\ Identifying best practices in adoption, implementation and enforcement of flavoured tobacco product restrictions and bans: lessons from experts
}

\author{
Katherine Peck, ${ }^{1}$ Rebekah Rodericks 이, ${ }^{1}$ Lola Irvin, ${ }^{2}$ Lila Johnson, ${ }^{2}$ Jill Tamashiro, ${ }^{2}$ \\ Lance Ching, ${ }^{2}$ Tetine Sentell (1) , ${ }^{1}$ Catherine Pirkle (1) ${ }^{1}$
}

\begin{abstract}
- Additional supplemental material is published online only. To view please visit the journal online (http://dx.doi. org/10.1136/tobaccocontrol2020-055884)
\end{abstract}

${ }^{1}$ Office of Public Health Studies, University of Hawai'i at Mānoa, Honolulu, Hawai'i, USA

${ }^{2}$ Chronic Disease Prevention and Health Promotion Division, Hawai'i State Department of Health, Honolulu, Hawai'i, USA

\section{Correspondence to}

Rebekah Rodericks, Office of Public Health Studies, University of Hawai'i at Mānoa, Honolulu, HI 96822, USA;

rebekah7@hawaii.edu

Received 1 May 2020

Revised 7 September 2020

Accepted 12 September 2020

\begin{abstract}
Objective To identify recommended components

for adopting, implementing and enforcing bans or restrictions targeting flavoured tobacco products.

Methods Between April and June 2019, semistructured interviews were conducted with 17 high-level experts across the USA and Canada with expertise in flavoured tobacco product policies. Participants included health department staff, researchers, legal professionals and local government officials. Interviews were recorded, transcribed and analysed for key themes.

Results Major findings were organised into four categories: programme planning and legislative preparations; education and community outreach; implementation and enforcement; and policy impact. Critical pre-implementation elements included using comprehensive policy language, identifying enforcement agents, examining potential economic costs, deploying media campaigns and engaging community partners and retailers. Recommended implementation processes included a 6-month preparation timeline, focus on retailer education and clearly outlined enforcement procedures, particularly for concept flavours.

Conclusions Flavoured tobacco policies have successfully limited sales, withstood legal challenges and become more comprehensive over time, providing useful lessons to inform ongoing and future legislative and programmatic efforts. Identifying and sharing best practices can improve passage, implementation, efficacy and evaluation of flavoured tobacco policies.
\end{abstract}

\section{INTRODUCTION}

Flavoured tobacco product restrictions and bans have become an increasingly popular response to widespread use of electronic cigarettes (e-cigarettes), electronic smoking devices (ESDs) and vape products in local jurisdictions across the USA. Although the US Food and Drug Administration (FDA) enacted a federal ban on cigarettes with characterising flavours (such as cherry or chocolate) in $2009,{ }^{1}$ several limitations have allowed flavoured tobacco products to proliferate. The exemption of menthol, as well as the introduction and extraordinary growth of flavoured e-cigarettes, has contributed to the growing use of tobacco products among youth and vulnerable adult populations. ${ }^{2}$ The most recent National Youth Tobacco Survey indicates that nearly $28 \%$ of high school age youth currently use e-cigarettes, reversing consistent declines in overall tobacco use since the 1990 s and mobilising legislators, communities, educators and concerned parents to action. ${ }^{3}$

To date, over 270 US localities across nine states have passed restrictions on the sale of flavoured tobacco products (which include e-cigarettes, ESDs and vape products in the USA), and eight states have enacted emergency rules to temporarily restrict e-cigarette sales. ${ }^{4}$ In November 2019, Massachusetts became the first state to pass a flavoured tobacco product ban inclusive of vapes and menthol cigarettes. ${ }^{5}$ FDA guidance remains incomplete, as 2020 enforcement priorities for electronic nicotine delivery systems (ENDS) continue to exclude tobacco-flavoured and menthol-flavoured ENDS products, as well as all flavours of e-liquids for open tank ENDS. ${ }^{6}$ In the absence of a comprehensive federal-level ban, this wave of legislative action is expected to continue.

Model policy language exists to guide the creation of flavoured tobacco bans and restrictions. ${ }^{78}$ Strong evidence also exists demonstrating the efficacy of these policies in restricting access to flavoured tobacco products in the USA and Canada. ${ }^{9-13}$ However, there is less information available on procedures surrounding policy adoption, implementation and enforcement. Legislation alone does not ensure its effective policy implementation, and a better understanding of best practices can help policies achieve public health goals. Considering the vested interest of tobacco companies, vaping businesses and some retail organisations in actively undermining flavoured tobacco product restrictions, policy implementation could be impeded without incorporation of best practices.

Given the rapid expansion of flavoured tobacco policies across the USA, this study sought to identify factors critical to effective policy implementation through key informant interviews with experts across the USA and Canada. This study emerged from a project for the Hawai'i Department of Health (DOH) to inform state legislative efforts. Despite previous successes in passing progressive tobacco regulations, including being the first US state to raise the legal age of sale and possession of all tobacco products (including e-cigarettes) to 21 years, ${ }^{14}$ rates of vaping for middle and high school age youth in Hawai'i are among the highest nationally (16\% and 26\%, respectively). ${ }^{15}$ Menthol use among Native Hawaiian and Filipino youth 
and adult populations is also high. ${ }^{16-18}$ While this project was prompted by Hawai'i's programmatic and legislative efforts, it draws on experiences from diverse experts across North America, providing important and applicable implementation considerations for other states and localities.

\section{METHODS}

\section{Key informant selection}

University of Hawai'i at Mānoa (UH) Healthy Hawai'i Initiative Evaluation Team research staff received recommendations for nine experts with flavoured tobacco policy knowledge and experience from Hawai'i DOH and other colleagues. A brief literature search identified eight additional key tobacco experts. Individuals were considered experts due to their first-hand involvement with passing, implementing, enforcing, evaluating and/or researching flavoured tobacco bans and restrictions across one or more jurisdictions. Some experts were well-known individuals with decades of experience, while others had recently played a key role in contributing to flavour bans.

Between April and June 2019, the research team conducted interviews with 17 experts across the USA $(n=15)$ and Canada $(n=2)$. These included eight health department staff, four university researchers, two legal professionals, two local government officials and one researcher from a national organisation. Several individuals held dual appointments or roles.

\section{Study instruments and procedures}

Using a standardised semistructured interview guide, all participants were asked about an ideal timeline, efficacy of implementation in their jurisdiction, evaluation considerations, lessons learnt, menthol-specific challenges, economic impacts and unforeseen consequences (see online supplemental file for full interview guide). These topics stemmed from a review of current literature, which aimed to identify facilitators and barriers to successful implementation of flavoured tobacco product restrictions and inform the language and content of the interview guide. Additional probes were added when speaking to subject matter experts on particular issues, and the guide was updated with an additional question pertaining to flavoured tobacco product lists.

Two research staff conducted a total of 14 interviews (11 with individual participants, 3 with pairs of participants) using the online platform Zoom. The average interview lasted 46 min. Recordings were transcribed by a professional transcription service and then reviewed and cleaned. Transcribed text was transferred from Microsoft Word documents to Excel for data management and systematic coding. Written consent was obtained from all participants.

\section{Data analysis}

Interviews were deductively and inductively analysed using the framework method by two research staff (KP, RR) to identify key themes. The framework method is a useful approach for thematic analysis of semistructured interview transcripts and also supports the emergence of new or additional themes. ${ }^{19}$ Some key themes, such as the value of education campaigns, the need for clear enforcement mechanisms and the importance of anticipating industry pushback, were expected from the existing research literature, while others emerged from the analysis including policy adoption procedures. In both cases, text was aggregated by code to identify compelling quotations and meaningful subthemes.

\section{RESULTS}

Participants had experience with a variety of flavoured tobacco bans and restrictions: policies inclusive of vape products and e-cigarettes; policies exclusive to traditional tobacco products; comprehensive bans without any exemptions; as well as partial bans, including restrictions exempting menthol, restrictions exempting adult-only retailers and location-dependent restrictions (eg, sales restriction to a certain distance from schools). Based on the interview guide and thematic analysis, key findings were organised into four overarching categories: (1) programme planning and legislative preparations, (2) education and community outreach, (3) implementation and enforcement, and (4) policy impact. It was anticipated that findings would focus primarily on implementation and enforcement processes; however, it quickly became apparent from interviews that the policy passage and adoption phases should not be assessed separately, as legislative and pre-implementation factors are critical to successfully implementing and enforcing a flavour ban.

\section{Programme planning and legislative preparations}

Participants widely recognised that comprehensive bans on flavoured tobacco products set a strong foundation for effective implementation (table 1). As one participant described, 'Look at the places which have exceptions. Those laws are much harder to enforce, because the rule is complex. If you just say, "we're not allowing the sale of flavored tobacco products, period," it's also easier for the retailers because they don't have to get into these questions.'

In a variety of contexts, partial bans and exemptions have proven difficult to enforce, requiring additional legislation to address unforeseen consequences. For example, several jurisdictions described that in response to policies exempting adultonly retailers, convenience stores had sectioned off retail space to create 'adult-only' spaces to sell flavoured tobacco products. Specifically pertaining to the drafting of legislation, several participants highlighted the need for comprehensive language to avoid such loopholes.

Additional legislative considerations included predetermining responsible actors for enforcement and ensuring these parties had requisite statutory authority for enforcement. There was consensus that penalties written into the proposed legislation should target retailers, not users, especially not underage users.

Menthol was identified as an essential, but challenging element. Some indicated that if menthol was excluded from tobacco legislation, key advocates would likely withhold their support. Several participants strongly framed flavour bans as a health equity issue, highlighting the need to reach populations historically targeted by the tobacco industry (racial/ethnic minorities; sexual and gender minorities; and adolescents) to ensure they achieved equal protection under the new policy. As one participant reflected, 'The people with the least resources, the people that are least informed, the folks that are in the most precarious position, are the ones using this product. If we're going to deal with health disparities, then we have to deal with that issue. Menthol is at the core.' Yet, some participants recognised the political expedience of exempting menthol from policies, considering its high value to the tobacco industry and to local and state governments given associated revenues generated from tobacco taxes.

Regarding potential economic and financial considerations of a flavour ban, one common argument against adopting similar policies is that retailers will be forced to close their businesses 
Table 1 Concepts and themes to consider related to programme planning and legislative preparations for a state-wide flavoured tobacco ban

\begin{tabular}{|c|c|c|}
\hline Themes & Codes & Sample responses \\
\hline Full comprehensive ban & $\begin{array}{l}\text { Value of full ban to promoting public health and health equity. } \\
\text { Partial bans have proven difficult to enforce. } \\
\text { Partial bans can have unintended consequences. }\end{array}$ & $\begin{array}{l}\text { 'My biggest personal takeaway for any tobacco policy is, when it comes } \\
\text { to any new bill or law that goes through, once it's passed, people will } \\
\text { adjust. That's why I'm like really trying to push to make it as strong as } \\
\text { possible, because if it passes, if it goes through, they'll adjust. Everyone } \\
\text { will get used to it.' }\end{array}$ \\
\hline Menthol & $\begin{array}{l}\text { Valuable partner support could be lost if menthol excluded. } \\
\text { Need to include priority populations historically targeted by } \\
\text { industry. } \\
\text { Framing this as a health equity issue is important for building } \\
\text { support. } \\
\text { Assessing political readiness: recognise that menthol is valuable to } \\
\text { industry and state revenue. }\end{array}$ & $\begin{array}{l}\text { 'If it (Hawai'i's ban) doesn't include menthol, a number of health groups, } \\
\text { like the group I work with, would not support this.' } \\
\text { 'And the reason these people are using these products, it's not because } \\
\text { they were born to do it. It's because the industry has very successfully } \\
\text { targeted them and taken advantage of them. And to leave menthol } \\
\text { out, which is the most important cigarette flavor, is to leave the most } \\
\text { vulnerable behind.' }\end{array}$ \\
\hline Legislative considerations & $\begin{array}{l}\text { Critical to include comprehensive language in bill to avoid } \\
\text { loopholes. } \\
\text { Identifying responsible actors and granting authority sets the stage } \\
\text { for successful implementation and enforcement. } \\
\text { Include penalties for retailers, not users. }\end{array}$ & $\begin{array}{l}\text { 'It's just important not to leave loose ends like that unresolved. If you } \\
\text { have people who are inspecting, you've got to give them the authority } \\
\text { to do their job completely, or else you have to go back to the drawing } \\
\text { board and rewrite. Even making a small change to legislation is a pretty } \\
\text { big lift, so it's best to try to put all that authority in the law the first time } \\
\text { around.' }\end{array}$ \\
\hline $\begin{array}{l}\text { Economic and financial } \\
\text { considerations }\end{array}$ & $\begin{array}{l}\text { Accounting for potential programme costs. } \\
\text { Limited evidence of retailers going out of business as the result of } \\
\text { flavour bans or restriction. } \\
\text { Communicate that tobacco regulation will inevitably lead to } \\
\text { reductions in state revenues and the need for alternative sources of } \\
\text { funding. } \\
\text { Building the case for long-term health expenditure savings from } \\
\text { tobacco cessation. }\end{array}$ & $\begin{array}{l}\text { 'If a state is relying on the sale of a product that's killing half of the } \\
\text { people who are using it to fund anything, it's problematic. I think we } \\
\text { know that the healthcare costs that are going to be saved as a result of } \\
\text { decreasing dependency on smoking cigarettes, or any of their tobacco } \\
\text { products, far, far outweigh the revenue that we generated through } \\
\text { taxation...And similarly, I think if retailers are relying on the sale of } \\
\text { this product as their main lifeblood for staying in business, it might be } \\
\text { time to consider selling a different product that's not so dangerous and } \\
\text { damaging to clientele.' }\end{array}$ \\
\hline
\end{tabular}

due to lost revenue. However, participants consistently reported limited evidence of retailers closing due to flavour bans.

\section{Education and community outreach}

Media campaigns were identified as important to increasing general awareness of flavoured tobacco products, their health impacts and details of the proposed policy (table 2). Respondents recommended that both flavoured tobacco and mentholspecific campaigns should be employed to educate the public about the risks associated with these products, and that menthol campaigns could specifically expose exploitation by the tobacco industry. According to one participant: 'Raising broad awareness of that as an issue both helps lay the groundwork for effective enforcement and will also help build support for legislation...
I would try to start as aggressive and loud a public education campaign on these issues as possible.'

Several participants strongly suggested that advertisements for cessation resources complement any campaign, and requisite funding should be set aside for this purpose.

Identifying and engaging community partners throughout the legislative and implementation process emerged as a clear message across multiple jurisdictions. It was recommended that community members, especially priority populations, be at the centre of policy and campaign efforts to shape messaging, inform educational efforts and mitigate potential misunderstandings of a proposed policy. Engaging youth was also identified as a highly effective approach, particularly in the legislative setting, recognising that the organised, coordinated turn-out of youth

Table 2 Concepts and themes to consider related to education and community engagement for a state-wide flavoured tobacco ban

\begin{tabular}{|c|c|c|}
\hline Themes & Codes & Sample responses \\
\hline Media campaigns & $\begin{array}{l}\text { Flavoured tobacco campaign critical to increasing general awareness. } \\
\text { Menthol campaign needed to expose exploitation, spread awareness } \\
\text { of risks. } \\
\text { Advertising cessation resources should complement any campaign. }\end{array}$ & $\begin{array}{l}\text { 'There needs to be a public health media campaign that gets this message } \\
\text { home about the importance and the problems with flavored tobacco } \\
\text { products, and there needs to be cessation services made available to } \\
\text { people who want to quit.' }\end{array}$ \\
\hline Retailers as partners & $\begin{array}{l}\text { Retailers should be valued as partners; overall they want to cooperate } \\
\text { but need support. } \\
\text { Anticipate initial pushback: loss of retail sales is a common concern. }\end{array}$ & $\begin{array}{l}\text { 'Based on our experience, you know, the retailer engagement is absolutely } \\
\text { key. They're hopefully partners in this effort, and not just people to be } \\
\text { regulated...Ensuring compliance with the policy [is easier] when they are } \\
\text { on board with it, and in our experience most retailers genuinely want to } \\
\text { comply with the policies.' }\end{array}$ \\
\hline Community partners & $\begin{array}{l}\text { Community members need to be at the centre of planning and action. } \\
\text { Native Hawaiian, Pacific Islander and Filipino leadership key to building } \\
\text { a broader coalition to advance health equity. } \\
\text { Engaging youth can also be highly effective. } \\
\text { Organised, coordinated turn-out public hearings critical in legislative } \\
\text { process. } \\
\text { Other key actors could include law enforcement, religious groups, } \\
\text { military and tourism industry. }\end{array}$ & $\begin{array}{l}\text { 'You have to engage the community that you're regulating....you can't } \\
\text { regulate a population that uses it at very high rates, and that are addicted, } \\
\text { without engaging that population.' }\end{array}$ \\
\hline
\end{tabular}


and community activists in public hearings has been important in other settings. Other suggested key actors include law enforcement and religious groups. It was portrayed that strong local engagement can heighten pressure on elected officials, lead to increased ownership of an issue or specific policy and build community commitment to effective implementation.

Treating tobacco retailers as partners also emerged as an important theme. Respondents cautioned about coordinated retailer advocacy in opposition to proposed legislation due to concerns about lost sales, particularly for specialty shops. At the same time, participants stated that retailers generally want to comply with a new policy, but need support to fully understand the intent, criteria and implications of flavoured tobacco legislation.

\section{Implementation and enforcement procedures}

An ideal timeline to prepare for implementation was identified as 3-12 months (table 3). It was noted that local, state and federal rules and regulations could impact the timeline. Six

Table 3 Concepts and themes to consider related to implementation and enforcement of a state-wide flavoured tobacco ban

\begin{tabular}{|c|c|c|}
\hline Themes & Codes & Sample responses \\
\hline Implementation timeline & $\begin{array}{l}\text { Ideal implementation timeframe identified as 3-12 months. } \\
\text { Need to understand how local, state and federal rules and } \\
\text { regulations could impact timeline. } \\
\text { Widely acknowledged that a grace period was critical for education, } \\
\text { selling off flavoured tobacco product and allowing for warning } \\
\text { visits. }\end{array}$ & $\begin{array}{l}\text { 'I would say three to six months. I think anything shorter than } \\
\text { three months is too fast, because there will just be chaos. Which is bad } \\
\text { for everybody, the retailers, the enforcement agencies, everybody else. I } \\
\text { think longer than six months, it starts dragging out and the momentum, } \\
\text { if you manage to get this thing through the legislature, it will be a big } \\
\text { loud fight. And the big loud fight will generate a lot of publicity, which } \\
\text { is itself very helpful in terms of establishing public awareness for proper } \\
\text { implementation. And if you wait too long...people forget about that.' }\end{array}$ \\
\hline Retailer education & $\begin{array}{l}\text { Knowing your retailers is key to creating effective and appropriate } \\
\text { educational materials. } \\
\text { One-on-one outreach is the most effective approach in providing } \\
\text { education and answering questions; may require volunteer support. } \\
\text { Additional communication approaches could include a hotline, } \\
\text { textline and web postings. } \\
\text { Be clear with messaging for retailers: create low-literacy materials } \\
\text { and translate for store owners as needed, and include visual images } \\
\text { of flavoured products as a training tool. } \\
\text { Town halls were not identified as a useful approach for retailer } \\
\text { education. } \\
\text { Vendors, wholesalers and distributors can be useful allies in } \\
\text { reaching retailers. }\end{array}$ & $\begin{array}{l}\text { 'Many of our retailers don't fully understand the difference between } \\
\text { tobacco product and a nicotine product and an e-juice. They're selling } \\
\text { these products, but they don't understand necessarily what has nicotine } \\
\text { and what doesn't have nicotine. And so having to explain that and be } \\
\text { really precise about the really nuanced products that are out there can } \\
\text { be challenging, especially when a vendor is not happy to see you to } \\
\text { begin with.' }\end{array}$ \\
\hline $\begin{array}{l}\text { Responsible agencies for } \\
\text { enforcement }\end{array}$ & $\begin{array}{l}\text { No one set approach to enforcement: other jurisdictions often } \\
\text { involved health department and law enforcement. } \\
\text { Assessing current capacity and responsibilities will help identify } \\
\text { who is in the best position. } \\
\text { Most jurisdictions did not hire additional staff to enforce a } \\
\text { restriction or ban. }\end{array}$ & $\begin{array}{l}\text { 'There's a wide range of agencies, ranging from the health departments, } \\
\text { to local police departments, to code enforcement...some jurisdictions } \\
\text { have dedicated licensing entities that handle...all business licensing. I } \\
\text { think it really comes down which agency has the infrastructure in place } \\
\text { to do it most effectively.' }\end{array}$ \\
\hline $\begin{array}{l}\text { Concept flavours and product } \\
\text { lists }\end{array}$ & $\begin{array}{l}\text { Concept flavours identified as among the single biggest challenges } \\
\text { and evolving issues. } \\
\text { Need a set protocol for identifying concept flavours. } \\
\text { Flavoured tobacco product lists have been attempted in many } \\
\text { jurisdictions but were widely seen as ineffective and impossible to } \\
\text { maintain. } \\
\text { Non-flavoured tobacco product lists identified as a potential } \\
\text { approach to addressing this issue. }\end{array}$ & $\begin{array}{l}\text { 'I know that in State__, they were curating a list of flavored tobacco } \\
\text { products that they were certifying as flavored tobacco. That list is } \\
\text { dozens and dozens and dozens of pages. It's very dense. I think what } \\
\text { worked for them is they had folks who were sort of living and breathing } \\
\text { tobacco compliance and were able to know the ins and outs of all of } \\
\text { those products. Our enforcement team, there's just no way for them to } \\
\text { be living and breathing hundreds and thousands of products and if the } \\
\text { color red is somehow flavored today but wasn't flavored yesterday.' }\end{array}$ \\
\hline
\end{tabular}


months was identified as the average amount of time to erect the necessary infrastructure. Participants acknowledged that grace periods were critical for education, permitting retailers to sell down flavoured tobacco inventories, and enforcement agents to conduct warning visits. Several respondents stressed that policies should be implemented as soon as possible to avoid loss of momentum and public interest, while others emphasised that too short of an implementation period could be chaotic for retailers and enforcement agencies. A slightly longer timeline was expected for state-wide bans to coordinate all of the key players.

Retailer education was widely seen as a key step in the implementation phase and was regarded as a lengthy, resourceintensive process. Several participants noted that knowledge of existing retailers was critical in creating appropriate educational materials. One-on-one outreach was generally regarded as the most effective approach in providing education and answering questions, and in some jurisdictions, this required volunteer support from the community.

Town halls were resoundingly rejected as a useful approach for retailer education, as this format is often inaccessible for retailers working long hours and leads to venting of frustration by the most vocal critics rather than targeted education and relationship building.

Respondents clearly indicated that there is no single approach to enforcement of flavoured tobacco regulations. Commonly involved parties included departments of health and law enforcement, but no two jurisdictions involved the same array of actors. Stand-alone fines were not seen as an effective deterrent for retailers. The participants firmly conveyed that a combination of fines, suspensions and revocations would be necessary, noting that this approach is currently employed in many jurisdictions. Closely related, determining an appeals process was identified as an important consideration.

Establishing procedures for identifying flavours was also highlighted as a key element, including the use of sniff tests and processes for contestation. Concept flavours (tobacco products with characterising flavours not clearly identifiable as fruit, dessert or menthol) were one of the most important challenges and evolving enforcement issues. Products combining menthol and fruit flavours were also recognised as attempts to evade regulatory language. Participants reinforced the importance of setting clear protocols for identifying concept and combination flavours. However, it was cautioned that creating comprehensive lists of banned products was nearly impossible to maintain as the number of products proliferates into the tens of thousands.

An alternative suggestion was to create a list of non-flavoured tobacco products that can be sold as opposed to maintaining a list of banned products. This recommendation would entail developing a certification, approval and appeals process. For example, manufacturers would certify under oath, with a penalty for making a false statement, that their products do not contain characterising flavours. The designated enforcement agency would then be responsible for product review and approval. Though not yet attempted, a non-flavoured product list would put the onus on the tobacco industry to prove that their products are not flavoured, reducing work for public enforcement agents.

\section{Policy impact}

Several participants reinforced the importance of baseline data collection prior to passage and implementation of flavour policies to demonstrate impact (table 4). Participants highlighted the importance of disaggregated data focusing on vulnerable populations, data targeting flavours and menthol separately, and collecting information specific to different geographies. Of particular note, participants mentioned the limited data regarding internet sales, which has not been identified as a key purchasing outlet in many jurisdictions where policies have been passed.

Participants uniformly stated that bans or restrictions in their jurisdiction had been successfully implemented. Typically, this was evidenced by high retailer compliance based on purchase and inspection data. At the same time, past and pending litigation and the potential for legislative pre-emption were perceived as constant threats across jurisdictions large and small. Several respondents saw coordinated industry pushback throughout the legislative and implementation processes as proof of the impact of these tobacco policies. According to one participant, 'This is really striking at the heart of their new markets...This is one of those issues that isn't going to be over for a while, because the industry is going to counterattack. But that's just evidence about how important it is.' Still, participants from some jurisdictions felt that lawsuits at the local level were hindering broader action at the state level.

\section{DISCUSSION}

By exploring common themes across flavoured tobacco regulatory efforts at multiple levels of governance, we sought to inform policy and programmatic efforts in Hawai'i and elsewhere. Our findings suggest that across North America, flavoured tobacco policies have largely been implemented successfully and are increasingly comprehensive in scope. Tobacco policy experts are clearly learning from one another and building on efforts in other jurisdictions. As an evolving area, additional data are still needed to evaluate and assess the impact of these policies. In addition to analysing tobacco usage rates and utilisation of cessation resources, potential indicators to evaluate and assess impact include monitoring sales tax revenue, conducting telephone surveys with retailers or intercept surveys, gathering data on the response of tobacco distributors or other key players and bringing confiscated products to legislative hearings as evidence.

We also identified commonalities in the successful passage and implementation of flavoured tobacco policies. Salient aspects involved deep engagement of community members and retailers. Community advocates can play a central role in policy change as well as implementation by applying pressure to elected officials or enforcement authorities, educating community members and addressing resistance from coordinated retailers or other opposition groups. Retailer education emerged as possibly the most important and time-intensive aspect of implementation, and a number of studies to date have demonstrated that retail compliance with flavoured tobacco product restrictions is generally high. $^{9101213}$

While initially this study meant to focus on implementation and enforcement, participants did not dissociate policy passage from implementation processes, which is consistent with literature on the policy stages/cycle heuristic. ${ }^{20} \mathrm{~A}$ variety of critical pre-implementation factors emerged, including the creation of strong and comprehensive policy language to dictate predetermined enforcement roles and close loopholes, public education campaigns meant to sensitise citizens and legislators to the importance of flavoured tobacco policies and promotion of cessation resources including state quitlines and youth-focused services. While key to priming implementation and enforcement, many of these elements could be pursued immediately, even prior to passage, and active planning efforts could help avoid some 
Table 4 Concepts and themes to consider related to policy impact of a state-wide flavoured tobacco ban

\begin{tabular}{|c|c|c|}
\hline Themes & Codes & Sample responses \\
\hline Evaluation of flavour policies & $\begin{array}{l}\text { Potential indicators could include purchase data, smoking/vaping } \\
\text { rates, use of cessation resources and marketing data. } \\
\text { Potential data sources could include point of sales data, } \\
\text { household and school surveys, observational assessments in } \\
\text { stores or development of a special survey/new questions to } \\
\text { integrate into existing surveys. } \\
\text { Importance of baseline data and gathering relevant information } \\
\text { prior to passage and implementation to demonstrate impact. } \\
\text { Importance of disaggregated data: asking about different target } \\
\text { populations, specifically about flavours and menthol separately, } \\
\text { information specific to different geographies. } \\
\text { Little data collected in other jurisdictions on internet sales. } \\
\text { Passage of multiple tobacco policies complicates efforts to } \\
\text { attribute causation and behaviour change. }\end{array}$ & $\begin{array}{l}\text { 'We also have some data specifically looking at what is the store } \\
\text { environment. Have there been changes? Now the caveat to that is } \\
\text { that we're like a policy incubator, right?...We've had tobacco } 21 \text { has } \\
\text { happened locally and statewide. We've got this flavor restriction and } \\
\text { now one of our supervisors has proposed eliminating the sales of } \\
\text { e-cigarettes altogether. So there's a lot of things that pop in and it } \\
\text { makes it really hard to parse out and even evaluate what thing, what } \\
\text { levers are changing behavior, even if we do see behavior changing... } \\
\text { So there's just a lot of activity which is good, but not good from a } \\
\text { scientific, let's figure out how to measure this, perspective.' }\end{array}$ \\
\hline $\begin{array}{l}\text { Perceived success of bans and } \\
\text { restrictions }\end{array}$ & $\begin{array}{l}\text { High compliance and retailer cooperation assessed across } \\
\text { jurisdictions, primarily from in-store inspections. } \\
\text { Most retailers want to be in compliance once the policy passes, } \\
\text { but may need help understanding the nuances of flavoured } \\
\text { products. } \\
\text { Flavour bans are still an emerging area, but recognition that more } \\
\text { evaluation data are needed to demonstrate impact. } \\
\text { Full bans are easier to implement and evaluate than partial } \\
\text { restrictions. } \\
\text { Awareness that implementation challenges exist (eg, concept } \\
\text { flavours, illicit products). }\end{array}$ & $\begin{array}{l}\text { 'Overall the compliance has been pretty good and I don't think } \\
\text { we've seen tremendous backlash. I think small businesses aren't } \\
\text { super happy about it, but they're also compliant, which is really } \\
\text { appreciated.' } \\
\text { '"How do you know if it's effective?" ...I say the reason that the } \\
\text { tobacco industry is sitting here is because from the effects of policy... } \\
\text { The industry recognizes this is a very effective policy and they're } \\
\text { willing to spend a lot of money to protect it.' }\end{array}$ \\
\hline Lawsuits and industry pushback & $\begin{array}{l}\text { Past and pending litigation is a constant threat across } \\
\text { jurisdictions. } \\
\text { Many saw coordinated industry pushback throughout the } \\
\text { legislative and implementation processes as proof of impact. } \\
\text { Be aware of Data Practice Act (DPA) issues: the public (including } \\
\text { the tobacco industry) has the right to request copies of public } \\
\text { government data, so be careful about what is put in writing. }\end{array}$ & $\begin{array}{l}\text { 'We really couldn't go the state level, because we needed to start } \\
\text { with the cities and towns and then go up, which is what kind of sucks } \\
\text { about the lawsuits, because the industry has such a big presence } \\
\text { in our state house. I just would never undermine that. They're } \\
\text { everywhere. Really, they have legislators' ears and they are the small } \\
\text { businesses in all of these cities and towns and counties. They're the } \\
\text { life blood of the system, etc. etc. It was very hard to counter that.' }\end{array}$ \\
\hline
\end{tabular}

unforeseen consequences experienced elsewhere. For example, when legislation failed to include language to allow inspectors to seize flavoured tobacco products or issue violations during enforcement checks, this required amendments to provide inspectors with additional authority. Thus, implementation and enforcement issues identified by the key informants were directly related to the earlier policy adoption phase.

In addition to policy passage considerations, participants identified common challenges to implementation and enforcement. Respondents involved with partial bans or restrictions including geographic, adult-only and menthol exemptions saw workarounds and unintended consequences that necessitated further legislative action. The emergence of concept flavours and difficulties identifying flavoured tobacco products were generally recognised as leading challenges to consistent enforcement, causing confusion for both government agents and retailers who struggled to track the proliferation of new products. Reliance of governments on tobacco taxes to fund critical services and infrastructure was a resonant frustration among respondents. It has proven difficult in some contexts to quantify potential revenue losses associated with menthol-flavoured tobacco products.

While few studies have qualitatively examined flavoured tobacco implementation and enforcement processes, there is a body of literature focused on evaluating implementation of flavoured tobacco restrictions using point of sales data in places including New York City, Boston, Minneapolis and Saint Paul. $^{9101213}$ Findings from these studies demonstrate high overall retailer compliance with restrictions, and that the availability of flavoured tobacco products for purchase decreased following policy implementation, reinforcing participants' general perceptions of impact. Additionally, qualitative studies have sought to examine implementation and enforcement of other types of tobacco policies across various locations in North America. Several echoed findings from this analysis, including the value of education campaigns and media engagement ${ }^{102122}$; the role of local organisations, actors and partnerships ${ }^{22-25}$; and strong enforcement mechanisms. ${ }^{21}$ Key challenges resonant with our findings included issues with policy loopholes, ${ }^{24}$ retailer opposition $^{10}$ and industry pushback and lawsuits. ${ }^{1021}$

Though there exist jurisdiction-level case studies examining the implementation of flavoured tobacco policies, ${ }^{10}$ to our knowledge, no other work attempts to compare experiences across North America to identify commonalities and best practices for implementation. Given the number of localities across the USA that have passed or are poised to act to address epidemic levels of vaping among youth and adult populations, this study has important practical applications. Among study strengths, the sample of respondents had experience with multiple types of policies in the USA and Canada. Overall, respondents were candid and forthcoming in their responses, and both internal and published findings corroborated key findings. Multiple research staff participated in each interview, reviewed transcripts and collaborated in the coding process to ensure quality of results.

While saturation of themes was reached, one limitation is a relatively small sample size. While this study included experts of diverse experiences and geographies, the sample size did not allow for subgroup analyses. Some of the findings may not be generalisable or adaptable as the respondents' expertise is based on specific political, economic, geographic and organisational climates that can influence policy implementation and enforcement. In addition, many of these conversations took place months or years after policy adoption, passage and implementation; 
therefore, it is possible that some of the findings were affected by recall bias.

Regulation of flavoured tobacco products, particularly e-cigarettes, is a fast-moving and highly dynamic health policy frontier in the USA and elsewhere. The rapidly evolving nature of this issue, influenced by emergency proclamations, potential US FDA changes and self-regulatory actions on the part of corporations including Juul, will likely influence implementation and enforcement options. For instance, it is doubtful that some jurisdictions, in attempting to act quickly and decisively, will have the luxury of 12-month preparation timeline or protracted educational efforts with their retailer populations. However, planning for successful implementation and enforcement will be relevant regardless of the time constraints or policy mechanisms. Comprehensive language, robust engagement, strong non-compliance measures, clear enforcement procedures and authority, and early consideration of evaluation measures were all identified as supportive elements. Readiness to respond to policymaker and retailer concerns about potential economic losses from tobacco sales, addressing the growing challenge of identifying concept flavours, and anticipating potential industry pushback could help avert or mitigate major issues. In highlighting best practices as well as common challenges, we hope to contribute to successful adoption, implementation and evaluation of flavoured tobacco policies that demonstrate their long-term impacts on public health.

\section{What this paper adds}

- The growing use of flavoured tobacco products, particularly in the form of electronic cigarettes, is leading to increased policy and regulatory action in the USA and elsewhere.

- While there exists model policy language to guide legislative efforts, limited research has focused on identifying best practices in policy implementation and enforcement related to flavoured tobacco products.

- Flavoured tobacco policies in the USA and Canada have successfully limited sales, withstood legal challenges and become more comprehensive over time, providing useful lessons to inform ongoing and future legislative and programmatic efforts.

- Recommended implementation processes included a 6-month timeline, focus on retailer education and clearly outlined enforcement procedures, particularly for concept flavours.

Acknowledgements We would like to thank the Hawai'i State Department of Health's Chronic Disease Prevention and Health Promotion Division and the Hawai'i Public Health Institute for providing meaningful insights during the development of the interview guide and the data interpretation phase. We would also like to express our thanks and appreciation to all of the key informants who took time to participate in this study and share their valuable expertise and lessons learnt with tobacco control colleagues in other states and jurisdictions.

Contributors KP and RR were responsible for designing the study, conducting interviews, overseeing the qualitative analysis and drafting the article. TS and CP advised on conceptualising and designing the study, developing a plan for qualitative analysis, and assisted with editing the article. LJ, JT, LC and LI assisted with conceptualising the study, interpreting the data and editing the article. All authors contributed substantially to article preparation, reviewing and approving the final product.

Funding This project was funded by the Hawai'i State Department of Health's Chronic Disease Prevention and Health Promotion Division, through a contract with the University of Hawai'i's Office of Public Health Studies, Healthy Hawai'i Initiative Evaluation Team.

Competing interests None declared.

Patient consent for publication Not required
Ethics approval The UH Office of Research Compliance's Human Studies Program determined this study protocol to be exempt (UH IRB No 2019-00063).

Provenance and peer review Not commissioned; externally peer reviewed.

Data availability statement Data are available upon reasonable request. Deidentified data may be provided for public health-related requests that include reasonable justification.

Open access This is an open access article distributed in accordance with the Creative Commons Attribution Non Commercial (CC BY-NC 4.0) license, which permits others to distribute, remix, adapt, build upon this work non-commercially, and license their derivative works on different terms, provided the original work is properly cited, appropriate credit is given, any changes made indicated, and the use is non-commercial. See: http://creativecommons.org/licenses/by-nc/4.0/.

\section{ORCID iDs}

Rebekah Rodericks http://orcid.org/0000-0002-0639-881X

Tetine Sentell http://orcid.org/0000-0003-3548-1281

Catherine Pirkle http://orcid.org/0000-0002-1528-5438

\section{REFERENCES}

1 U.S. Food and Drug Administration. Family smoking prevention and tobacco control act - an overview, 2018. Available: https://www.fda.gov/tobacco-products/rulesregulations-and-guidance/family-smoking-prevention-and-tobacco-control-actoverview [Accessed 19 Nov 2019].

2 Public Health Law Center. Regulating flavored tobacco products, 2019. Available: https://publichealthlawcenter.org/sites/default/files/resources/Regulating-FlavoredTobacco-Products-2019-2.pdf [Accessed 19 Nov 2019].

3 Cullen KA, Gentzke AS, Sawdey MD, et al. E-Cigarette use among youth in the United States, 2019. JAMA 2019:322:2095-103.

4 Campaign for Tobacco Free Kids. States \& localities that have restricted the sale of flavored tobacco products, 2020. Available: https://www.tobaccofreekids.org/assets/ factsheets/0398.pdf [Accessed 6 Aug 2020].

5 Romo V. Massachusetts governor signs law severely restricting flavored tobacco, vape products. NPR, 2019. Available: https://www.npr.org/2019/11/27/783400051/ massachusetts-governor-signs-law-severely-restricting-flavored-tobacco-vape-prod [Accessed 27 Nov 2019].

6 U.S. Food and Drug Administration. Enforcement priorities for electronic nicotine delivery system (ends) and other deemed products on the market without Premarke authorization, 2020. Available: https://www.fda.gov/regulatory-information/searchfda-guidance-documents/enforcement-priorities-electronic-nicotine-delivery-systemends-and-other-deemed-products-market [Accessed 6 Aug 2020].

7 ChangeLab Solutions \& California Department of Public Health. Model California ordinance restricting the sale of menthol cigarettes and other flavored tobacco products, 2018. Available: https://www.changelabsolutions.org/product/policyoptions-restricting-sales-menthol-cigarettes-and-other-flavored-tobacco-products [Accessed 19 Nov 2019].

8 Tobacco Control Legal Consortium. Sample language to restrict the sale of flavored tobacco products including menthol, 2014. Available: https://www. publichealthlawc enter.org/sites/default/files/resources/tclc-fs-sample-flavored-tobacco-language-2014. pdf [Accessed 19 Nov 2019].

9 Brock B, Carlson SC, Leizinger A, et al. A tale of two cities: exploring the retail impact of flavoured tobacco restrictions in the twin cities of Minneapolis and Saint Paul, Minnesota. Tob Control 2019:28:176-80.

10 Brown EM, Rogers T, Eggers ME, et al. Implementation of the New York City policy restricting sales of flavored non-cigarette tobacco products. Health Educ Behav 2019:46:782-9.

11 Chaiton M, Schwartz R, Shuldiner J, et al. Evaluating a real world ban on menthol cigarettes: an interrupted time-series analysis of sales. Nicotine Tob Res 2020;22:576-9.

12 Farley SM, Johns M. New York City flavoured tobacco product sales ban evaluation. Tob Control 2017;26:78-84

13 Kephart L, Setodji C, Pane J, et al. Evaluating tobacco retailer experience and compliance with a flavoured tobacco product restriction in Boston, Massachusetts: impact on product availability, advertisement and consumer demand. Tob Control 2019. doi:10.1136/tobaccocontrol-2019-055124. [Epub ahead of print: 14 Oct 2019].

14 Irvin LH, Johnson L, Yamauchi J, et al. Insights in public health: formative factors for a statewide tobacco control advocacy infrastructure: insights from Hawai'i. Hawai'i j Med Public Health 2019;78:66-70.

15 Hawai'i State Department of Health. Hawai'i school health survey: youth risk behavior survey module, 2017. In: Hawai'i health data warehouse indicator-based information system for public health, 2018. http://ibis.hhdw.org/ibisph-view/

16 Hawai'i State Department of Health. Hawai'i school health survey: youth tobacco survey module, 2017. In: Hawai'i health data warehouse indicator-based information system for public health, 2018. http://ibis.hhdw.org/ibisph-view/

17 Hawai'i State Department of Health, Tobacco Prevention and Education Program, Chronic Disease Management and Control Branch. Smoking and tobacco use in 


\section{Original research}

Hawai'i: facts, figures, and trends, 2010. Available: https://health.hawaii.gov/ tobacco/ home/facts-table/ [Accessed 24 Mar 2020].

18 Corpuz KA, Dela Cruz MRI. Rates of current tobacco and electronic smoking device use among Filipinos in Hawai'i. Hawai'i J Health Soc Welf 2019;78:359-64.

19 Gale NK, Heath G, Cameron E, et al. Using the framework method for the analysis of qualitative data in multi-disciplinary health research. BMC Med Res Methodol 2013;13:117.

20 Benoit F. Public policy models and their usefulness in public health: the stages model. Montréal, Québec: National Collaborating Centre for Healthy Public Policy, 2013.

21 Crosbie E, Sebrié EM, Glantz SA. Strong advocacy led to successful implementation of smokefree Mexico City. Tob Control 2011;20:64-72.
22 Jin $\mathrm{Y}$, Berman $\mathrm{M}$, Klein $\mathrm{EG}$, et al. Ending tobacco sales in pharmacies: a qualitative study. J Am Pharm Assoc 2017;57:670-6.

23 Klein EG, Liber AC, Kauffman RM, et al. Local smoke-free policy experiences in Appalachian communities. J Community Health 2014;39:11-16.

24 Lencucha R, Ruckert A, Labonte R, et al. Opening windows and closing gaps: a case analysis of Canada's 2009 tobacco additives ban and its policy lessons. BMC Public Health 2018;18:1321.

25 Moreland-Russell S, Combs T, Schroth K, et al. Success in the city: the road to implementation of tobacco 21 and sensible tobacco enforcement in New York City. Tob Control 2016;25:i6-9. 